\title{
Genetic diversity of Poa pratensis L. depending on geographical origin and compared with genetic markers
}

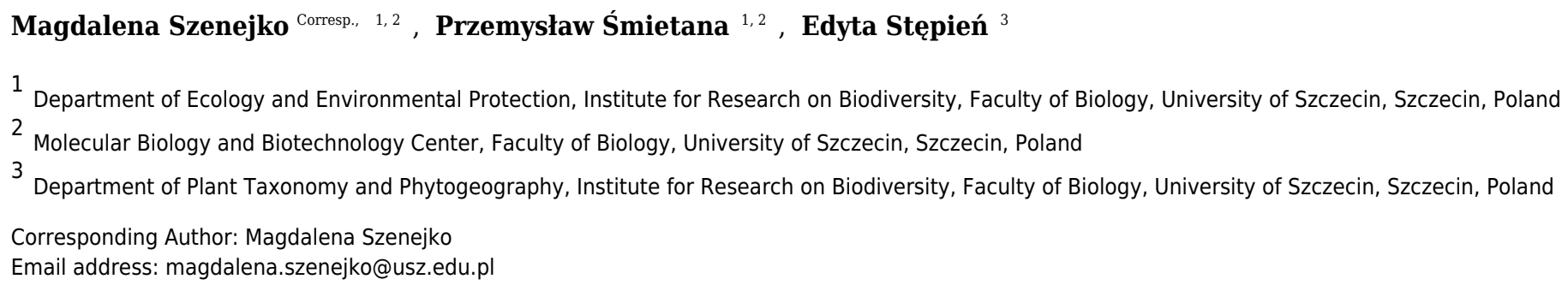

Background. Poa pratensis is one of the most common species of meadow grass in Europe. Most cultivars of the species found in Poland were originally derived from its ecotypes. We compared the effectiveness of the RAPD and ISSR methods in assessing the genetic diversity of the selected populations of $P$. pratensis. We examined whether these methods could be useful for detecting a possible link between the geographical origin of a given population and its assessed genetic variation. Methods. The molecular markers RAPD and ISSR were used and their efficiency compared using, inter alia, statistical multivariate methods (UPGMA and PCA). Results. The low value of Dice's coefficient (0.369) along with the significantly high percentage of polymorphic products indicates a substantial degree of genetic diversity among the studied populations. Our results found a correlation between the geographical origin of the studied populations and their genetic variations. For ISSR, which proved to be the more effective method in that respect, we selected primers with the greatest differentiating powers correlating to geographical origin. Discussion. The populations evaluated in this study were characterized by a high genetic diversity. This seems to confirm the hypothesis that ecotypes of $P$. pratensis originating from different regions of Central Europe with different terrain structures and habitat conditions can be a source of great genetic variability. 


\section{Genetic diversity of Poa pratensis L. depending on geographical origin and}

2 compared with genetic markers

3 Magdalena Szenejko ${ }^{1,2}$, Przemysław Śmietana ${ }^{1,2}$, Edyta Stępień ${ }^{3}$

$4{ }^{1}$ Department of Ecology and Environmental Protection, Institute for Research on Biodiversity, Faculty of Biology,

5 University of Szczecin, Szczecin, Poland

$6 \quad{ }^{2}$ Molecular Biology and Biotechnology Center, Faculty of Biology, University of Szczecin, Szczecin, Poland

7 3 Department of Plant Taxonomy and Phytogeography, Institute for Research on Biodiversity, Faculty of Biology,

8 University of Szczecin, Szczecin, Poland

10 Corresponding Author:

11 Magdalena Szenejko

12 Wąska 13, Szczecin, 71-415, Poland

13 Email address: magdalena.szenejko@usz.edu.pl

\section{Abstract}

16 Background. Poa pratensis is one of the most common species of meadow grass in Europe. 17 Most cultivars of the species found in Poland were originally derived from its ecotypes. We compared the effectiveness of the RAPD and ISSR methods in assessing the genetic diversity of the selected populations of $P$. pratensis. We examined whether these methods could be useful for detecting a possible link between the geographical origin of a given population and its assessed genetic variation.

22 Methods. The molecular markers RAPD and ISSR were used and their efficiency compared 23 using, inter alia, statistical multivariate methods (UPGMA and PCA).

\section{Results}

25 The low value of Dice's coefficient (0.369) along with the significantly high percentage of 26 polymorphic products indicates a substantial degree of genetic diversity among the studied 27 populations. Our results found a correlation between the geographical origin of the studied populations and their genetic variations. For ISSR, which proved to be the more effective method in that respect, we selected primers with the greatest differentiating powers correlating to geographical origin.

\section{Discussion}


32 The populations evaluated in this study were characterized by a high genetic diversity. This 33 seems to confirm the hypothesis that ecotypes of $P$. pratensis originating from different regions 34 of Central Europe with different terrain structures and habitat conditions can be a source of great 35 genetic variability.

\section{Introduction}

37 Poa pratensis L. is one of the most common species of meadow grass in Europe. It occurs 38 throughout the country and is highly valued as a grass cultivar that can be used for various purposes (Mirek \& Pięknoś-Mirkowa, 2007; Szenejko, 2014). Due to its high plasticity, high spreading capability and significant expansiveness, $P$. pratensis is considered a cosmopolitan species capable of occupying a wide range of different habitats. Its wide range of distribution and the ease with which the species adapts to very different conditions has resulted in a great diversity of ecotypes thriving in a miscellany of habitats. In the case of $P$. pratensis, the selection of particular ecotypes became the basis for breeding work. In Poland, most cultivars of the species were derived from natural grasslands, often from individual plants. Because apomixis is the dominant manner of reproduction in P. pratensis, achieving high genetic variability within individual populations is rather difficult (Müntzing, 1933; Muller, 1964; Felsenstein, 1974; Pamilo et al., 1987; Huff \& Bara, 1993). In addition to vegetative and sexual reproduction processes, the plant can also reproduce asexually from seeds, which are formed through apospory or diploid parthenogenesis and without any fertilization process (Mazzucato et al., 1996; Albertini et al., 2001; Spillane et al., 2001; Albertini et al., 2005; Matzk et al., 2005). As a result, offspring and parent plants may be genetically identical (Albertini et al., 2004; Carneiro et al., 2006). This implies that the initial forms i.e. the different ecotypes and cultivars used for breeding did not produce new combinations of genes. As a result, cultivars derived from such initial material have similar or related genotypes. The results of our earlier research, which concerned the evaluation of genetic variability in cultivars and ecotypes of $P$. pratensis native to Central Europe using RAPD markers, confirmed the considerable genetic relatedness of those cultivars and ecotypes (Szenejko et al., 2009; Szenejko \& Rogalski, 2015). The populations evaluated in those studies originated from Lower Silesia and Podlasie, regions of Poland with different habitats and climatic conditions. The ecotypes analyzed in those previous studies differed with respect to their phenotypic traits but showed little genetic variability, whereas the populations in the present study were selected from habitats as diverse as possible, i.e. lowlands, 
63 uplands and mountains. The ecotypes in this study originated from the western and southern 64 regions of Poland as well as from the Kujawy and Podlasie regions. It was assumed that long distances between regions would affect habitat conditions, and that natural spatial barriers would cause the greatest genotypic diversity among the research material. In addition, three cultivars (including two of the oldest Polish cultivars of $P$. pratensis) were included in our research and subjected to the same analyses. All the plant material was evaluated for genetic diversity using two systems of markers based on DNA amplification (RAPD and ISSR). In the present study, the effectiveness of the methods in assessing the genetic diversity of the selected forms of $P$. pratensis was compared. Furthermore, we investigated whether these methods could be useful in establishing a link between the geographical origin of a given population and their assessed genetic variability. Primers with the greatest differentiating powers correlating with geographical distance were selected for ISSR, the more effective method in that respect. Principal Component Analysis (PCA) was used for this procedure, which was performed on the chosen values of DNA amplification products obtained in the presence of those selected ISSR markers with the highest genetic differentiating power with respect to the studied forms of P. pratensis.

\section{Materials \& Methods}

\section{Plant material}

This assessment of the genetic diversity of 18 selected forms of $P$. pratensis was carried out in 2014. The study involved 3 cultivars and 15 ecotypes selected from locations as distant as possible from each other. The seeds used in the study came from the national collection of the Botanical Garden of the Institute of Plant Breeding and Acclimatization in Bydgoszcz (IHAR); the caryopses used for establishing this collection were collected during field trips organized by the staff of the Botanical Garden and originated from different geographical regions of Poland, including 8 different voivodships (provinces) (Fig. 1, Table 1). The main criteria when harvesting the caryopses were the diversity of plant material and variety of habitats. The seed material was collected from wastelands and arable land (meadows and pastures), as well as from environmentally valuable areas. The assessment of genetic diversity was performed for three cultivars used for different purposes, including 'Eska 46', one of the oldest Polish fodder cultivar and two lawn cultivars: 'Limousine', an apomictic uniclonal German cultivar, and 'Alicia', the oldest Polish lawn cultivar.

\section{DNA isolation}


94 Genomic DNA was isolated from the plant tissue using magnetic beads (NOVABEADS Plant

95 DNA STANDARD Purification KIT), following the procedure for monocotyledons and the 96 manufacturer's instructions (Novazym, Poland). For each form of P. pratensis 100-150 mg of

97 material was taken from 80 random etiolated seedlings. The DNA was isolated in two 98 repetitions.

\section{RAPD method}

100 RAPD analysis, based on random amplification of polymorphic DNA, was performed according 101 to the modified method described by Williams et al. (1990). Sixty-nine primers were tested and 7 102 were chosen to evaluate RAPD polymorphism (Table 2). The amplification reactions were 103 performed in a $\mathrm{T} 100^{\mathrm{TM}}$ Thermal Cycler (Bio-Rad Polska). The thermal profile proposed by 104 Rajasekar et al. (2005) was used: initial denaturation for 5 minutes at $95^{\circ} \mathrm{C}$, then $94{ }^{\circ} \mathrm{C}-1$ 105 minute, $37{ }^{\circ} \mathrm{C}-90$ seconds, and $72{ }^{\circ} \mathrm{C}-1$ minute in 45 cycles, with a final elongation for 7

106 minutes. The reactions were carried out on a total volume of $25 \mu 1$ containing the following 107 ingredients: 1xbufor for PCR reaction with $\mathrm{Mg}^{2+}$ (Novazym, Poland), $1.5 \mathrm{mM} \mathrm{MgCl} 2,0.2 \mathrm{mM}$ 108 dNTPs, $1.0 \mu \mathrm{M}$ primer, 1.25 U RedAllegro Taq Polymerase (Novazym, Poland) and $125 \mathrm{ng}$ of 109 DNA.

\section{ISSR method}

111 ISSR analysis was performed following the modified method described by Ziętkiewicz et al.

112 (1994) and the experimental conditions optimized by Wang (2010). Having pretested 66 113 microsatellite primers, 13 of these (Oligo IBB PAN, Poland) were chosen to evaluate ISSR 114 polymorphism (Table 2). The reaction mixture, $25 \mu 1$ in volume, contained: 1xbufor for the PCR 115 reaction with $\mathrm{Mg}^{2+}$ (Novazym, Poland), $1.5 \mathrm{mM} \mathrm{MgCl}_{2}, 0.25 \mathrm{mM} \mathrm{dNTP}, 0.4 \mu \mathrm{M}$ of primer $1 \mathrm{U}$ 116 RedAllegro Taq Polymerase (Novazym, Poland) and 50 ng of DNA.

117 The amplification reactions were carried out in a T100 ${ }^{\mathrm{TM}}$ Thermal Cycler (Bio-Rad Polska) for

11840 cycles. The ISSR PCR reaction was as follows: initial denaturation at $94{ }^{\circ} \mathrm{C}$ for 4 minutes, 119 then $94{ }^{\circ} \mathrm{C}-30$ seconds, $52{ }^{\circ} \mathrm{C}-45$ seconds, $72{ }^{\circ} \mathrm{C}-2$ minutes, with a final elongation carried 120 out at $72^{\circ} \mathrm{C}$ for 7 minutes.

\section{Data analysis}

122 The resulting RAPD and ISSR amplification products were separated on $2.0 \%$ agarose gel with 123 ethidium bromide ( $5 \mu \mathrm{g} / \mathrm{ml}$; Sigma-Aldrich) in a TAE buffer for 4-5 hours. Visualization, 124 documentation and analysis of the results were carried out using Gel Doc ${ }^{\mathrm{TM}} \mathrm{XR}+$ and Quantity 
125 One 4.6.5 software manufactured by Bio-Rad. The Polymorphism Information Content (PIC)

126 index for dominant primer systems was calculated for both RAPD and ISSR (Ghislain et al.,

127 1999). The Assay Efficiency Index (AEI) value was also calculated (Pejic et al., 1998). The

128 Genetic Similarity Index (Si) of the studied ecotypes and cultivars of P. pratensis was

129 determined in accordance with Dice's coefficient (Dice, 1945) following Nei and Li (1979). The

130 correlations between them were determined on the basis of genetic similarity matrices obtained

131 in the presence of the RAPD and ISSR markers by calculating Spearman's rank correlation

132 coefficient $(\mathrm{r} ; \mathrm{p}<0.05)$; then the determined genetic similarity matrix was used to construct

133 UPGMA dendrograms in FreeTree and TreeView 1.6.6 software (Pavlíček et al., 1999; Hampl et

134 al., 2001). To analyze the quality of information from particular RAPD and ISSR primers,

135 Principal Component Analysis (PCA) was used. The information on the size of the selected

136 amplification products obtained in the presence of each primer was used as the initial data; then

137 the PCA assessment was carried out by reducing three-dimensional space to two dimensions.

138 The results of multiple analyses were compared to the PCA results. The PCA results obtained

139 using the initial data, in the form of information on the geographical location of the place of

140 origin of particular ecotypes, was used as the target matrix. These analyses were carried out

141 using the STATISTICA 10.0 PL statistical package.

\section{Results}

\section{RAPD analysis}

144 In the course of RAPD analysis, in total 246 amplification products were obtained for which $145100 \%$ polymorphism was demonstrated (Table 3 ). The primers chosen to evaluate polymorphism 146 generated bands in a wide size range: from $149 \mathrm{bp}$ to $2367 \mathrm{bp}$ in the presence of primer $\mathrm{C} 16$. The 147 greatest number of amplicons (43) was obtained as the result of reactions with primers G19 and 148 M14 (Fig. 2). The primers used for the analysis initiated the synthesis of 79 specific 149 amplification products which differentiated the studied forms of $P$. pratensis. Of these, the 150 largest number of DNA fragments (16) which had a unique composition were obtained in 151 reaction with the M14 primer (Fig. 2). As many as 68 specific products were found for the 152 ecotypes, with the largest number of them in a population from Silesia (bes03 373). In the 153 presence of 6 primers, we were able to generate 15 products with a unique composition, ranging 154 in size from $149 \mathrm{bp}$ (for C16) to $1478 \mathrm{bp}$ (for M14). Unique DNA fragments of approximately 155 the same size were identified in amplification reactions with different primers. A significant 
156 number of specific bands were also identified for two ecotypes, one from Podkarpacie (bie04

157 189) and the other originating from the borderland region of Lubuskie and Lower Silesian

158 voivodships (provinces) (lbs05 628) 11 and 10 bands respectively.

\section{ISSR analysis}

160 As the result of amplification reactions involving 13 microsatellite primers, a total of 514 161 products ranging in size from $303 \mathrm{bp}$ (for 811) up to $3105 \mathrm{bp}$ (for 808) were obtained (Table 3 162 and Fig. 3). In reactions with primers N01 and 840 a large number of bands were generated (51 163 and 50 respectively), whereas in the presence of primer 807 only 23 products (the smallest 164 number) were obtained. A high level of polymorphism was observed in the amplified DNA 165 fragments and in the presence of 8 primers only polymorphic products were obtained. We 166 identified a total of 124 specific amplification products in the ecotypes and cultivars of $P$. 167 pratensis analyzed in this study. The largest number (17) was obtained in reaction with primer 168808 , while in the presence of primer 807 only one product with a unique composition (649 bp) 169 for ecotype lbs05 170 was obtained (Fig. 3). In total, 95 such products were identified for the 170 ecotypes. The largest numbers were recorded for populations lbs05 170 (15 bands) and lbs05 628 171 (13 bands), and for ecotype pom06 175. Specific products of similar molecular size were 172 identified in the presence of different primers. A significant number of unique bands were also 173 identified for the lawn cultivars, including the German 'Limousine' (11).

\section{Evaluation of RAPD and ISSR polymorphisms}

175 Using RAPD and ISSR markers, a significant number of specific amplification products were 176 obtained. $98.6 \%$ of the bands obtained using ISSR were polymorphic, whereas those obtained in 177 RAPD reactions were $100 \%$ polymorphic (Table 3). A large number of products were obtained 178 using both methods in the presence of single primers (on average 30 products for each method) 179 (Table 4). For both RAPD and ISSR methods the polymorphism information content (PIC) was 180 calculated; the average PIC value for each method was almost identical and was 0.264 for RAPD 181 and 0.270 for ISSR. The value of the assay efficiency index, which indicates the average number 182 of polymorphic products identified in the presence of a single primer, was also calculated for 183 both RAPD and ISSR marker systems. The obtained AEI value was higher for ISSR markers. 184 Specific DNA fragments were obtained for almost all the studied populations (Tables 3 and 4); 185 RAPD primers were more effective in identifying them. In a reaction with a single RAPD 186 primer, we were able to identify as many as 11 unique bands. Dice's genetic similarity matrix 
187 was determined for all the studied forms of $P$. pratensis. Independently of each other, the RAPD

188 and ISSR methods revealed little genetic relationship between the studied populations and 189 cultivars (Table 4). On average Dice's coefficient for RAPD was 0.371, while it was 0.367 for

190 ISSR markers. The greatest genetic relationship was demonstrated between two populations from

191 Podlaskie voivodship, pod02 215 and pod02 317 (0.733 for RAPD, 0.650 for ISSR and 0.678 for

192 RAPD+ISSR). The lowest values of Dice's coefficient for RAPD (0.154) were obtained for

193 populations lbs05 170 and bie04 189, while in the cases of ISSR and RAPD+ISSR the smallest

194 degree of genetic relatedness was found between ecotype lbs05 628 and the cultivar 'Alicia'. The

195 following ecotypes were found to be most genetically distant: bie04 189, lbs05 628, and lbs05

196 170. To highlight the compatibility of the results of the RAPD and ISSR methods, the correlation

197 between them was calculated. Using Spearman's coefficient (0.461), the statistical correlation

198 between the genetic similarity matrices obtained on the basis of electrophoretic images for

199 RAPD and ISSR was calculated (Fig. 4).

\section{Cluster analysis}

201 The applied measure of genetic similarity was used to construct UPGMA dendrograms (Fig. 5).

202 There was greater compatibility with respect to the clustered forms for the ISSR and

203 RAPD+ISSR dendrograms. Regardless of which method was used, two asymmetrical and

204 distinct major clusters were clearly distinguishable in each dendrogram. The majority of the

205 studied forms were assigned to the second cluster, within which two subclusters of similarity

206 were distinguishable 11 forms for RAPD and RAPD+ISSR and 12 forms for ISSR. In the ISSR

207 dendrogram, the first main cluster included two ecotypes from Kujawsko-Pomorskie (pom06

208 175) and from West Pomerania voivodships (zap00 240). The combined RAPD+ISSR analysis

209 also included ecotype dos01 405 from Lower Silesia. In the case of RAPD, the first main cluster

210 contained two other ecotypes (bie04 189 and ora03 178), while pom06 175 and zap00 240 were

211 assigned to the second main cluster and to both common subclusters (Fig. 5). Two ecotypes from

212 Lubuskie voivodship (lbs05 170 and lbs05 628) turned out to be genetically most distant. These

213 were not assigned to any pair or subcluster; this is visible in all the dendrograms (Fig. 5). These

214 populations also differed among themselves; this was confirmed by the value of Dice's similarity

215 index (0.224 for RAPD+ISSR). In the ISSR and RAPD+ISSR dendrograms, other genetically

216 different forms included an ecotype from Podkarpacie region (bie04 189), while in the RAPD

217 dendrogram, a form from Silesia (bes03 373) was genetically different. Among the cultivars, 
218 'Eska 46' was the most distinctly different: in the RAPD and ISSR dendrograms, it was

219 connected loosely with the second cluster, while the image obtained for RAPD+ISSR depicted it

220 as an unpaired form. In each of the dendrograms the ecotypes from Podlasie and the lawn

221 cultivars 'Alicia' and 'Limousine' formed a common subcluster of forms. In the RAPD

222 dendrogram, the Silesian population bes03 354 joined them, whereas in the ISSR and

223 RAPD+ISSR dendrograms this form was included in the second subcluster together with other

224 ecotypes from Silesia and populations from Lesser Poland and Lower Silesia. In the ISSR

225 diagram, dos01 405 was placed with ecotypes from Lower Silesia, while in the RAPD diagram it

226 was only loosely connected with the second cluster and in the RAPD+ISSR diagram it was

227 included in a different cluster.

228 Principal Component Analysis

229 We examined the position of the ecotypes of $P$. pratensis in two-dimensional space using 230 principal component analysis (PCA), which was carried out on the geographical coordinates of

231 the habitats from which the surveyed populations had come. Figure 6A depicts this analysis, 232 which was used as a reference template for the selection of primers with the highest 233 differentiating power. PCA was performed independently for RAPD and ISSR, using the 234 amplification products generated in the presence of individual primers. For each of the methods 235 the four starters were chosen which most clearly and coherently revealed the relationship 236 between the geographic location of the assessed ecotypes and their genetic variability. 237 Subsequently all possible combinations of the selected primers were analyzed for their main 238 components; this was done separately for RAPD, ISSR and (RAPD + ISSR). A total of 60 PCAs 239 were performed for the RAPD and ISSR primers, both for their combinations within one method 240 and also for both methods combined. For the final PCA, DNA amplification products were 241 chosen which had been obtained from the studied ecotypes and cultivars of $P$. pratensis in the 242 presence of ISSR microsatellites 807, 808, 834 and 840; these were the dinucleotide repeat 243 sequences $(A G)_{n}(G A)_{n}$, anchored at the end of 3'. The studied populations were distributed on 244 both sides of the axis of coordinates and distinctly away from its center. They formed five 245 separate groups, which indicates their considerable diversity. Three populations from Podlasie $246(13,14,15)$, and ecotypes from West Pomerania (2) and Kujawy regions (1) together with the 247 lawn cultivar 'Limousine' (17), formed two clearly distinguishable groups (Fig. 6). These were 248 distributed on the same side of the first axis (horizontal) and clearly differed from the remaining 
249 forms of $P$. pratensis, which originated from regions in southern and western Poland. Another 250 group, which was located on the opposite side of the second axis, contained two ecotypes 251 (dos01 468 and lbs05 $628(4,7)$ ) which came from the borderlands of the Lower Silesian and 252 Lubuskie voivodships respectively. Populations from Silesia (10) and Lesser Poland (11) were 253 also contained in this group. On the same side of the horizontal axis we find another group 254 containing the fodder cultivar 'Eska 46' (18) and three ecotypes $(3,5,9)$ from the Lubuskie, 255 Lower Silesian and Silesian voivodships respectively. In the course of the principal component 256 analysis, two forms of $P$. pratensis were identified (12 and 18 ('Alicia')), which were not 257 included in any of the groups. As with the UPGMA dendrograms, the population from 258 Podkarpacie (bie04 189) differed distinctly from the other ecotypes and constituted a distinct 259 genotype (Fig. 5 and 6).

\section{Discussion}

261 DNA markers have become a useful tool for breeding work and for evaluating the genetic 262 diversity of many different plant species, including the family Poaceae. Molecular analysis, in 263 conjunction with the characteristics of morphological traits, may be used to classify plants and 264 select the initial forms for creating new cultivars or breeding lines. In the case of P. pratensis, 265 this was confirmed by Shortell et al. (2009), Tamkoc \& Arslan (2010), Raggi et al. (2015) and 266 Yuan et al. (2015). In this study two markers (RAPD and ISSR) based on DNA amplification 267 reactions were used to assess the genetic diversity of ecotypes and cultivars of P. pratensis. 268 These methods do not require any prior information on the analyzed DNA sequence. They do not 269 take a lot of time and are also relatively simple and therefore quite universal. Furthermore they 270 require only a small amount of DNA; this is why they are often employed in the genetic 271 evaluation of different plant species. They can be used either in combination (Nkongolo et al., 272 2005; Alam et al., 2009; de Lima et al., 2011; Singh et al., 2011; Debajit et al., 2015) or 273 independently of each other (Al-Humaid \& Motawei, 2004; Wang, 2010; Guo et al., 2009; 274 Bednarskaya et al. 2014). In grasses, RAPD and ISSR markers are most commonly used to 275 evaluate genetic variability within and between populations, and for molecular characterization 276 and identification of different species and their hybrids, cultivars and genotypes (Posselt et al.,

277 2006; Pivorienė et al., 2008; Al-Humaid et al., 2011; Motawei \& Al-Ghumaiz, 2012; Madesis et

278 al., 2014; Yuan et al., 2014). In P. pratensis genetic analyses employing RAPD and ISSR focus 279 mainly on the identification of sexual and apomictic genotypes (Huff \& Bara, 1993; Mazzucato 
280 et al., 1995; Barcaccia et al., 1997, 1998; Stephens et al., 2006); the assessment of genetic 281 variability and identification of genotypes and cultivars (Lickfeldt et al., 2002; Ning et al., 2005;

282 Liang et al., 2009; Fard et al., 2012; Wang et al., 2012; Yuan et al., 2015); determining the 283 genetic relationships between different genotypes and species belonging to the genus Poa and 284 their hybrids (Johnson et al., 2002; Curley \& Jung, 2004; Patterson et al., 2005; Goldman, 2008; 285 Goldman, 2013); and identification of pathogens responsible for fungal diseases in grasses 286 (Hsiang et al., 2000). Both marker systems can generate high resolution band patterns and high 287 levels of polymorphism as high as $90 \%$. The presence of these markers resulted in a significant 288 number of amplification products in our study: 246 for RAPD and 514 for ISSR. However, ISSR gives better reproducibility of results, which can be explained by its use of longer primers (microsatellites) and higher annealing temperatures (Gostimsky et al., 2005; Reddy et al., 2000; Fernandez et al., 2002; Vaillancourt et al., 2008). Similarly, in previous studies concerning the assessment of the morphological and genetic variability of domestic ecotypes of $P$. pratensis originating from the areas of Lower Silesia and Podlasie (Szenejko \& Rogalski, 2015), RAPD primers F05, G19 and M14 proved to be most useful in the evaluation of polymorphisms. The highest number of DNA fragments were obtained in the presence of these primers. In the case of ISSR markers, as in the studies of Bednarskaya et al. (2014), better results were obtained in the presence of primers with dinucleotide repeat sequences $(\mathrm{AG})_{2},(\mathrm{GA})_{2}$ and $(\mathrm{AC})_{2}$, anchored at the end of 3'. As suggested by Al-Humaid et al. (2004, 2011), dinucleotide and trinucleotide repeats are abundant in genomes of fodder grasses and thus might constitute potential markers for assessing their genetic diversity and identifying their fungal diseases using the ISSR method. In grasses, $(\mathrm{CAC})_{\mathrm{n}},(\mathrm{CTC})_{\mathrm{n}}$ and $(\mathrm{GA})_{\mathrm{n}}$ and $(\mathrm{CA})_{\mathrm{n}}$ are particularly abundant. In the genus Poa, ISSR primers with dinucleotide $(\mathrm{AC})_{\mathrm{n}}(\mathrm{CA})_{\mathrm{n}}(\mathrm{GA})_{\mathrm{n}}$ and $(\mathrm{AG})_{\mathrm{n}}$ repeats turned out to be particularly useful for the identification and evaluation of genetic relationships between various species, including $P$. angustifolia, $P$. trivialis, $P$. arachnifera, $P$. pratensis, $P$. compressa, $P$. ligularis, and P. secunda and their hybrids (Goldman, 2008; Arslan \& Tamakoç, 2011). A high level of polymorphism was observed in numerous amplification products generated in the course of our analyses. The nature of ISSR, which targets regions especially rich in microsatellites, may also explain the high level of polymorphism, since those regions are known to accumulate a large number of mutations due to DNA polymerase slippage during replication and unequal crossingover (Kashi \& King, 2006; da Costa et al., 2011). In the case of ISSR markers, this can lead to 
311 longer dinucleotide repeat sequences and insertion into at least one of them. In this way new

312 variants of microsatellite sequences of different lengths appear, which enriches the collection of

313 alleles identified as polymorphic in a population. However, according to many researchers, in the

314 course of RAPD and ISSR analyses significant levels of polymorphism can be generated, and for

315 various forms and species belonging to the genus Poa this can exceed 90\% (Liang et al., 2009;

316 Arslan \& Tamkoç, 2011; Fard et al., 2012; Wang et al., 2012; Cichorz et al., 2014). In our

317 analyses, a slightly greater percentage of polymorphic DNA fragments was obtained in reaction

318 with RAPD primers. The data available in the literature indicates that the RAPD method is

319 somewhat superior due to its higher levels of generated polymorphism in the presence of various

320 molecular marker systems which is explained, inter alia, by their polyallelic nature (Alam et al.,

321 2009; Bhattacharya et al., 2010; Naik et al., 2010). A possible explanation for the difference in

322 resolution of RAPD and ISSR is that the two-marker techniques target different portions of the

323 genome (Debajit et al., 2015). Although a greater percentage of polymorphic DNA products was

324 identified in the presence of RAPD primers, it was microsatellites that we found to be more

325 effective in detecting them. This finding was confirmed by calculating the average efficiency

326 index (AEI), which was slightly higher for ISSR markers. The slight differences in the

327 assessment of RAPD and ISSR polymorphisms did not rule out the possibility of establishing a

328 correlation between them. Even though Spearman's coefficient was not very high $(0.461)$, the

329 result was statistically very significant. Hence it can be concluded that the results presented in

330 this study obtained using RAPD and ISSR markers are comparable. Budak et al. (2004), in a

331 study examining the phylogenetic relationships between seed and vegetative biotypes of Buchloe

332 dactyloides, used various systems of molecular markers (ISSR, SSR, RAPD and SRAP), for

333 which they determined correlations. In the case of RAPD and ISSR, the Spearman's coefficient

334 (0.461) calculated by Budak was similar to ours, but their results turned out to be statistically

335 insignificant. Both RAPD and ISSR markers revealed a small genetic similarity among the

336 studied ecotypes and cultivars of $P$. pratensis. The average value of Dice's coefficient for both

337 methods combined (RAPD+ISSR) was low (0.369), which together with the high number of

338 polymorphic products may indicate substantial genetic differences between the studied

339 populations and their low level of relatedness. It can be speculated that natural spatial barriers

340 might have inhibited and minimized the transfer of genes among these populations; this would

341 certainly have contributed to their diversity. At the same time, we can surmise that there were 
342 populations among the studied ecotypes in which apomixis was the main mode of reproduction.

343 The ecotypes originating from three voivodships (Podkarpackie, Lower Silesian and Lubuskie

344 (bie04 189, lbs05 628 and lbs05 170)), were determined to be those genetically most distant from

345 the other forms. These populations had the lowest similarity index and included the most

346 uncommon genotypes, for which the largest number of specific amplification products were

347 identified. In comparison to the other cultivars, 'Eska 46' was clearly different in terms of its

348 genetic structure, and, overall, few amplification products were generated for it. It should be

349 stressed that in previous studies aimed at evaluating RAPD polymorphism in different

350 populations of $P$. pratensis, such a high genetic diversity among ecotypes had never been found,

351 while the average Dice's coefficient was about 0.7 (Szenejko \& Rogalski, 2015). Other authors

352 also reported significant genetic relatedness among the different genotypes and cultivars of $P$.

353 pratensis (Johnson et al., 2002; Ning et al., 2005; Tamkoc \& Arslan, 2010; Fard et al., 2012).

354 UPGMA dendrograms based on genetic similarity matrices revealed discrepancies in the mode

355 of clustering of the studied forms of $P$. pratensis. Greater similarity in that respect was

356 demonstrated for the ISSR and RAPD+ISSR methods. This difference in the clustering process

357 between the RAPD and ISSR dendrograms was also demonstrated in research by Bhattacharya et

358 al. (2010), who were assessing the genetic diversity of Cymbopogon winterianus and by

359 Souframanien \& Gopalakrishna (2004), who were studying genotypes of Vigna mungo. Similarly

360 to our results, these authors found greater clustering conformity for ISSR and RAPD+ISSR.

361 Looking at the distribution in individual UPGMA dendrograms, it appears that the ISSR

362 dendrogram depicts the relationship between the geographical origin of the ecotypes and their

363 genetic similarity in the clearest way. With the exception of populations bie04 189, lbs05 628

364 and lbs05 170, which differed from the others genetically, the remaining ecotypes were clustered

365 according to their geographical distribution. In the course of PCA, and depending on their

366 geographical origin, a similar tendency in the distribution of the studied populations in two-

367 dimensional space was observed. It was noted that ecotypes from the same voivodships

368 (provinces) or from regions located not far from one another were depicted similarly in two-

369 dimensional space as in the UPGMA dendrogram constructed for the ISSR process. Those

370 populations from eastern Poland and from West Pomerania and Kujawy clearly differed from the

371 ecotypes originating from the western and southern parts of the country and were located on the

372 opposite side of the horizontal axis of coordinates. They also differed from one another, which 
373 can be seen in their arrangement on both sides of the vertical axis. Some discrepancies were

374 found between the UPGMA and PCA clusters of the studied forms, which were related, inter 375 alia, to the distribution of the cultivars. Only a modest relationship between genetic divergence 376 and geographical origin in P. pratensis was reported by several authors (Johnson et al., 2002; 377 Fard et al., 2012; Raggi et al., 2015). For comparison, Abbaszade et al. (2013), who were 378 studying the genetic diversity of Lolium multiflorum, and Rahmati et al. (2013), who were 379 studying Festuca arundinacea, demonstrated a greater result consistency between UPGMA and 380 PCA. However, neither of these research teams was able to demonstrate a correlation between 381 the genetic variability of the grass genotypes they analyzed and their geographical origin.

\section{Conclusions}

383 Our results suggest that both the systems of dominant RAPD and ISSR markers that were used in 384 our research can be used to assess the genetic variability of selected ecotypes and cultivars of $P$.

385

386

387

388

389

390

391

392

393

394

395

396

397

398

399

400

401

pratensis. However, given their better reproducibility of results, greater efficiency in detecting polymorphic amplification products in the presence of a single primer and also their differentiating properties (which make them capable of distinguishing studied forms with respect to their genetic structure), ISSR markers seem to be a more useful and reliable tool for this kind of analysis. The plant material evaluated in this study was characterized by a high genetic variability, which seems to confirm the hypothesis that ecotypes of $P$. pratensis originating from different parts of Central Europe, each with different terrain structures and habitat conditions, can provide great genetic variability and a large collection of alleles. Microsatellites with dinucleotide repeat sequences $(\mathrm{AG})_{\mathrm{n}},(\mathrm{GA})_{\mathrm{n}}$ anchored at the end of 3 ' proved particularly useful for assessing the genetic diversity of these ecotypes and determining their main directions of variability. PCA helped to establish a correlation between the geographical origin of the studied ecotypes and their genetic variation.

\section{Acknowledgments}

We wish to express our gratitude to Anna Kalinka, $\mathrm{PhD}$ from the Department of Cell Biology, Faculty of Biology, University of Szczecin for sharing with us her invaluable advice and knowledge regarding the development and interpretation of RAPD and ISSR results.

\section{References}


402 Abbaszade S, Jafari AA, Safari H, Shirvani H. 2013. Genetic diversity of Lolium multiflorum 403 accessions using ISSR molecular markers. International Journal of Farming and Allied Sciences 404 2: 1217-1222.

405 Alam MdA, Naik PK, Mishra GP. 2009. Congruence of RAPD and ISSR markers for evaluation 406 of genomic relationship among 28 populations of Podophyllum hexandrum royle from Himachal 407 Pradesh, India. Turkish Journal of Botany 33: 1-12. DOI: 10.3906/bot-0711-10

408 Albertini E, Porceddu A, Ferranti F, Reale L, Barcaccia G, Romano B, Falcinelli M. 2001. 409 Apospory and parthenogenesis may be uncoupled in Poa pratensis: a cytological investigation. 410 Sexual Plant Reproduction 14: 213-217. DOI: 10.1007/s00497-001-0116-2

411 Albertini E, Marconi G, Barcaccia G, Raggi L, Falcinelli M. 2004. Isolation of candidate genes 412 for apomixis in Poa pratensis L. Plant Molecular Biolology 56: 879-894. DOI: 10.1007/s11103413 004-5211-y

414 Albertini E, Marconi G, Reale L, Barcaccia G, Porceddu A, Ferranti F, Falcinelli M. 2005. 415 SERK and APOSTART. Candidate genes for apomixis in Poa pratensis. Plant Physiology 138: 416 2185-2199. DOI: http://dx.doi.org/10.1104/pp.105.062059

417 Al-Humaid A, Motawei MI. 2004. Molecular characterization of some turfgrass cultivars using 418 randomly amplified polymorphic DNA (RAPD) markers. Journal of Food, Agriculture and 419 Environment 2: 376-380.

420 Al-Humaid A, Motawei MI, Abdalla MY, Mana F. 2004. Detection of genetic variation and 421 Fusarium resistance in turfgrass genotypes using PCR-based markers (ISSR and SCAR). Journal 422 of Food, Agriculture and Environment 2: 225-229.

423 Al-Humaid A, Ibrahim GH, Motawei MI. 2011. Molecular identification of some turfgrass 424 cultivars and their resistance to Fusarium graminearum. Australian Journal of Crop Science 5: $425 \quad 1754-1759$.

426 Arslan E, Tamkoç A. 2011. The application of ISSR-PCR to determine the genetic relationship 427 and genetic diversity between narrow leaved bluegrass (Poa angustifolia) and rough bluegrass 428 (Poa trivialis) accessions. Turkish Journal of Botany 35: 415-423. DOI:10.3906/biy-0912-31

429 Barcaccia G, Mazzucato A, Belardinelli A, Pezzotti M, Lucretti S., Falcinelli M. 1997. 430 Inheritance of parental genomes in progenies of Poa pratensis L. from sexual and apomictic 431 genotypes as assessed by RAPD markers and flow cytometry. Theoretical and Applied Genetics 432 95: 516-524. 
433 Barcaccia G, Veronesi F, Falcinelli M. 1998. Mapping of AFLP and RAPD markers linked to 434 apomeiosis in Medicago falcata and to parthenogenesis in Poa pratensis. Apomixis Newsletter 435 10: $2-7$.

436 Bednarskaya IA, Popov VN, Dugar YuN, Akinina GE, Dolgova TA. 2014. ISSR analysis of 437 some species of Angustifoliate Fescue. Cytology and Genetics 48: 364-370.

438 Bhattacharya S, Bandopadhyay TK, Ghosh PD. 2010. Efficiency of RAPD and ISSR markers in 439 assessment of molecular diversity in elite germplasms of Cymbopogon winterianus across West 440 Bengal, India. Emirates Journal of Food Agriculture 22: 13-24.

441 Budak H, Shearman RC, Parmaksiz I, Dweikat I. 2004. Comparative analysis of seeded and 442 vegetative biotype buffalograsses based on phylogenetic relationship using ISSRs, SSRs, 443 RAPDs, and SRAPs. Theoretical and Applied Genetics 109: 280-288. DOI: 10.1007/s00122444 004-1630-z

445 Carneiro VTC, Dusi DMA, Ortiz JPA. 2006. Apomixis: Occurrence, applications and 446 improvements. In: Teixeira da Silva JA, ed. Ornamental and Plant Biotechnology: Advances and 447 Topical Issues (I), Floriculture. Isleworth: 564-571.

448 Cichorz S, Gośka M, Litwiniec A. 2014. Miscanthus: Genetic diversity and genotype 449 identification using ISSR and RAPD markers. Molecular Biotechnology 5: 911-924.

450 Da Costa MLM, Amorim LLB, Onofre AVC, De Melo LJOT, De Oliveira MBM, De Carvalho 451 R, Benko-Iseppon AM. 2011. Assessment of genetic diversity in contrasting sugarcane varieties 452 using inter-simple sequence repeat (ISSR) markers. American Journal of Plant Sciences 2: 425453432.

454 Curley J, Jung G. 2004. RAPD-based genetic relationships in Kentucky bluegrass: comparison of 455 cultivars, interspecific hybrids, and plant introductions. Crop Science 44: 1299-1306. 456 DOI:10.2135/cropsci2004.1299

457 Debajit S, Sukriti D, Sneha G, Mohan L, Singh BB. 2015. RAPD and ISSR based Intra-specific 458 molecular genetic diversity analysis of Cymbopogon flexuosus L. Stapf with a distinct correlation 459 of morpho-chemical observations. Research Journal of Biotechnology 10: 105-113.

460 Dice LR. 1945. Measures of the amount of ecological association between species. Ecology 26: $461 \quad 297-302$. 
462 Fard JR, Zamani Z, Moghaddam MRF, Mohsen K. 2012. Evaluation of genetic diversity among 463 some genotypes of Kentucky bluegrass by RAPD molecular markers. Horticulture, Environment, 464 and Biotechnology 53: 298-303. DOI: 10.1007/s13580-012-0120-5

465 Felsenstein J. 1974. The evolutionary advantage of recombination. Genetics 78: 737-756.

466 Fernández ME, Figueiras AM, Benito C. 2002. The use of ISSR and RAPD markers for 467 detecting DNA polymorphism, genotype identification and genetic diversity among barley 468 cultivars with known origin. Theoretical and Applied Genetics 104: 845-851. DOI: 469 10.1007/s00122-001-0848-2

470 Ghislain M, Zhang D, Fajardo D, Huamann Z, Hijmans RH. 1999. Marker-assisted sampling of 471 the cultivated Andean potato Solanum phureja collections using RAPD markers. Genetic 472 Resources and Crop Evolution 46: 547-555.

473 Goldman JJ. 2008. The use of ISSR markers to identify Texas bluegrass interspecific hybrids. 474 Plant Breeding 127: 644-646. DOI: 10.1111/j.1439-0523.2008.01526.x

475 Goldman J. 2013. Genetic relationships in advanced generation hybrids derived from crosses 476 between Texas (Poa arachnifera) and Kentucky (Poa pratensis) bluegrass using ISSR markers. 477 American Journal of Plant Sciences 4: 2440-2443. http://dx.doi.org/10.4236/ajps.2013.412303

478 Gostimsky SA, Kokaiva G, Konovalov FA. 2005. Studying plant genome variation using 479 molecular markers. Russian Journal of Genetics 41: 378-388. DOI: 10.1007/s11177-005-0101-1

480 Guo HB, Huang KY, Zhou TS, Wu QH, Zhang YJ, Liang ZS. 2009. DNA isolation, optimization 481 of ISSR-PCR system and primers screening of Scutellaria baicalensis. Journal of Medicinal 482 Plant Research 3: 898-901.

483 Hampl V, Pavliček A, Flegr J. 2001. Construction and bootstrap analysis of DNA fingerprinting484 based phylogenetic trees with the freeware program Free Tree: application to trichomonad 485 parasites. International Journal of Systematic and Evolutionary, Microbiology 51: 731-735. 486 DOI: $10.1099 / 00207713-51-3-731$

487 Hsiang T, Ma XL, Yang L, Cook S. 2000. Analyses of RAPD data for detection of host 488 specialization in Sclerotina homoecarpa. Plant Pathology 49: 269-275. DOI: 10.1046/j.1365$489 \quad 3059.2000 .00445 . x$

490 Huff DR, Bara JM. 1993. Determining genetic origins of aberrant progeny from apomictic 491 Kentucky bluegrass using a combination of flow cytometry and silver stained RAPD markers. 492 Theoretical and Applied Genetics 87: 201-208. 
493 Johnson RC, Johnston WJ, Golob CT, Nelson MC, Soreng RJ. 2002. Characterization of the

494 USD Poa pratensis collection using RAPD markers and agronomic descriptors. Genetic 495 Resources and Crop Evolution 49: 349-361.

496 Kashi Y, King D. 2006 Simple sequence repeats as advantageous mutators in evolution. Trends

497 in Genetics 22: 253-259. DOI:10.1016/j.tig.2006.03.005

498 Liang M, Gao L, Chen YJ, Zhang ZY. 2009. Classification and genetic diversity of Kentucky

499 bluegrass by using RAPD markers. Journal Northeast Agricultural University (English Edition)

500 16: 9-13.

501 Lickfeldt DW, Voigt TB, Hamblin AM. 2002. Cultivar composition and spatial patterns in

502 Kentucky bluegrass blends. Crop Science 42: 842-847. DOI:10.2135/cropsci2002.8420

503 De Lima RSN, Daher RF, Gonçalves LSA, Rossi DA, Do Amaral Jr AT, Pereira MG, Lédo FJS.

504 2011. RAPD and ISSR markers in the evaluation of genetic divergence among accessions of

505 elephant grass. Genetics and Molecular Research 10: 1304-1313. DOI 10.4238/vo110-3gmr1107

506 Madesis P, Abraham EM, Kalivas A, Ganopoulos I, Tsaftaris A. 2014. Genetic diversity and

507 structure of natural Dactylis glomerata L. populations revealed by morphological and

508 microsatellite-based (SSR/ISSR) markers. Genetics and Molecular Research 13: 4226-4240.

509 Matzk F, Prodanovic S, Bäumlein H, Schubert I. 2005. The inheritance of apomixis in Poa

510 pratensis confirms a five locus model with differences in gene expressivity and penetrance. The

511 Plant Cell 17: 13-24. DOI: http://dx.doi.org/10.1105/tpc.104.027359

512 Mazzucato A, Barcaccia G, Pezzotti M, Falcinelli M. 1995. Biochemical and molecular markers

513 for investigating the mode of reproduction in the facultative apomicts Poa pratensis L. Sexual

514 Plant Reproduction 8: 133-138. DOI: 10.1007/BF00242256

515 Mazzucato A, Den Nijs APM, Falcinelli M. 1996. Estimation of parthenogenesis frequency in

516 Kentucky bluegrass with auxin-induced parthenocarpic seeds. Crop Science 36, 9-16.

517 DOI:10.2135/cropsci1996.0011183X003600010002x

518 Mirek Z, Pięknoś-Mirkowa H. 2007. Grasses Mountains. In: Frey L, ed. The Book of Polish

519 Grasses. Kraków (PL): W. Szafer Institute of Botany PAS, 203-228. (in Polish)

520 Motawei MI, Al-Ghumaiz NS. 2012. Genetic diversity in some introduced pasture grass cultivars

521 revealed by inter-simple sequence repeats (ISSR) markers. African Journal of Biotechnology 11:

522 3531-3536. DOI: 10.5897/AJB11.2577 
523 Muller HJ. 1964. The relation of recombination to mutational advance. Mutation Research 1: 2-

524 9. DOI:10.1016/0027-5107(64)90047-8

525 Müntzing A. 1933. Apomictic and sexual seed formation in Poa. Hereditas 17: 133-154.

526 Naik PK, Alam MDA, Singh H, Goyal V, Parida S, Kalia S, Mohapatra T. 2010. Assessment of

527 genetic diversity through RAPD, ISSR and AFLP markers in Podophyllum hexandrum: a

528 medicinal herb from the Northwestern Himalayan region. Physiology and Molecular Biology of

529 Plants 16: 135-148. DOI: 10.1007/s12298-010-0015-9

530 Nei M, Li WH. 1979. Mathematical model for studying genetic variation in terms of restriction

531 endonucleases. Proceedings of National Academy of Sciences of the USA Genetics 76: 52695325273.

533 Ning TT, Zhang ZJ, Jin CZ, Zhu YG. 2005. Genetic polymorphism of bluegrass cultivars 534 detected by RAPDs. Hereditas 27: 605-610.

535 Nkongolo KK, Michael P, Demers T. 2005. Application of ISSR, RAPD and cytological markers

536 to the certification of Picea mariana, P. glauca and P. engelmannii trees, and their putative

537 hybrids. Genome 48: 302-311. DOI: 10.1139/g04-118

538 Pamilo P, Nei M, Li WH. 1987. Accumulation of mutations in sexual and asexual populations.

539 Genetics Research 43: 135-146. DOI: 10.1017/S0016672300026938

540 Patterson JT, Larson SR, Johnson PG. 2005. Genome relationships in polyploidy Poa pratensis

541 and other Poa species inferred from phylogenetic analysis of nuclear and chloroplast DNA

542 sequences. Genome 48: 76-87. DOI: 10.1139/g04-102

543 Pavlíček A, Hrdá Š, Flegr J. 1999. FreeTree - freeware program for construction of phylogenetic

544 trees on the basis of distance data and bootstrap/jackknife analysis of the tree robustness.

545 Application in the RAPD analysis of genus Frenkelia. Folia Biologica (Prague) 45: 97-99. DOI:

$546 \quad 10.1099 / 00207713-51-3-731$

547 Pejic I, Ajmone-Marsan P, Morgante M. 1998. Comparative analysis of genetic similarity among

548 maize inbred lines detected by RFLPs, RAPDs, SSRs and AFLPs. Theoretical and Applied

549 Genetics 97: 1248-1255. DOI: 10.1007/s001220051017

550 Pivorienė O, Pašakinskienė I, Brazauskas G, Lideikytė L, Jensen LB, Lübberstedt T. 2008. Inter-

551 simple sequence repeat (ISSR) loci mapping in the genome of perennial ryegrass. Biologija 54:

$552 \quad 17-21$. 
553 Posselt UK, Barre P, Brazauskas G, Turner LB. 2006. Comparative analysis of genetic similarity 554 between perennial ryegrass genotypes investigated with AFLPs, ISSRs, RAPDs and SSRs. Czech 555 Journal of Genetics and Plant Breeding 42: 87-94.

556 Raggi L, Bitocchi E, Russi L, Marconi G, Sharbel TF. 2015. Understanding Genetic Diversity 557 and Population Structure of a Poa pratensis Worldwide Collection through Morphological, 558 Nuclear and Chloroplast Diversity Analysis. PLoS ONE 10: 1-22.

559 Rahmati H, Farshadfar M, Safari H, Shirvani H. 2013. Application of ISSR molecular markers in 560 genetic diversity of Festuca arundinacea. International Journal of Agriculture and Crop 561 Sciences 6: 286-291.

562 Rajasekar S, Fei S, Christians NE. 2005. Analysis of genetic diversity in rough bluegrass 563 determinate by RAPD markers. Crop Science 46: 162-167. DOI: 10.2135/cropsci2005.04-0008

564 Reddy MP, Sarla N, Siddiq EA. 2002. Inter simple sequence repeat (ISSR) polymorphism and its 565 application in plant breeding. Euphytica 128: 9-17. DOI: 10.1023/A:1020691618797

566 Shortell RR, Meyer WA, Bonos SA. 2009. Classification and inheritance of morphological and 567 agronomic characteristics in Kentucky bluegrass (Poa pratensis L.). HortScience 44: 274-279.

568 Singh DR, Srivastava AK, Srivastava A, Srivastava RC. 2011. Genetic diversity among three 569 Morinda species using RAPD and ISSR markers. Indian Journal of Biotechnology 10: 285-293.

570 Souframanien J, Gopalakrishna T. 2004. A comparative analysis of genetic diversity in 571 blackgram genotypes using RAPD and ISSR markers. Theoretical and Applied Genetics 109: 572 1687-1693. DOI: 10.1007/s00122-004-1797-3

573 Spillane C, Steimer A, Grossniklaus U. 2001. Apomixis in agriculture: The quest for clonal 574 seeds. Sexual Plant Reproduction 14: 179-187. DOI: 10.1007/s00497-001-0117-1

575 Stephens LC, Fei SZ, Xiong Y, Hodges CF. 2006. Plants regenerated from embryo cultures of an 576 apomictic clone of Kentucky bluegrass (Poa pratensis L. 'Baron') are not apomictic in origin. 577 Euphytica 147: 383-388. DOI: 10.1007/s10681-005-9034-y

578 Szenejko M. 2014. Kentucky bluegrass - a small but valuable cultivated grass of the temperate 579 climate zone. Kosmos. Problems of Biological Sciences 63: 107-116. (in Polish)

580 Szenejko M, Filip E, Słominska-Walkowiak R. 2009. Relationship between habitat conditions 581 and the degree of genetic diversity of ecotypes of Poa pratensis L. In: Naganowska B, Kachlicki

582 P, Krajewski P, eds. Genetics and genomics to improve crops. Poznań (PL): Institute of Plant 583 Genetics PAS, 343-350. (in Polish) 
584 Szenejko M, Rogalski M. 2015. Characterization of morphological traits and RAPD 585 polymorphism in selected forms of Kentucky bluegrass (Poa pratensis L.). Biodiversity 586 Research and Conservation 37: 1-10. DOI: 10.1515/biorc-2015-0005

587 Tamkoc A, Arslan E. 2010. Comparison of agronomic characters, total seed storage proteins and 588 their use for genotypes discrimination in the Kentucky bluegrass (Poa pratensis L.). 589 Biotechnology \& Biotechnological Equipment 24: 1573-1576. DOI:10.2478/V10133-010-0007-5

590 Vaillancourt A, Nkongolo KK, Michael P, Mehes M. 2008. Identification, characterisation, and 591 chromosome locations of rye and wheat specific ISSR and SCAR markers useful for breeding 592 purposes. Euphytica 159: 297-306. DOI: 10.1007/s10681-007-9492-5

593 Wang XM. 2010. Optimization of DNA isolation, ISSR-PCR system and primers screening of 594 genuine species of rhubarb, an important herbal medicine in China. Journal of Medicinal Plant 595 Research 4: 904-908. DOI: 10.5897/JMPR 10.077

596 Wang Ch, Li X, Gao LN, Zhang L, Liu W, Liu HM, Chen YJ. 2012. Study on classification and 597 genetic diversity of Kentucky bluegrass by using RAPD markers. Journal Northeast Agricultural 598 University (English Edition) 19: 37-41.

599 Williams JGK, Kubelik AR, Livak KJ, Rafalski JA, Tingey SV. 1990. DNA polymorphisms 600 amplified by arbitrary primers are useful as genetic markers. Nucleic Acids Research 18: 6531601 6535. DOI: 10.1093/nar/18.22.6531

602 Yuan X, Bao Z, He Y, Chen Q, Wang G. 2014. Development of SCAR marker related to 603 summer stress tolerance in Tall Fescue (Festuca arundinacea). Notulae Botanicae Horti 604 Agrobotanici Cluj-Napoca 42: 81-87.

605 Yuan X, He Y, Huang J, Hu W, Zhou H, Gao Q, Zhou S. 2015. Development of a SCAR marker 606 for rapid identification of new Kentucky bluegrass breeding lines. Notulae Botanicae Horti 607 Agrobotanici Cluj-Napoca 43: 79-85. DOI:10.15835/nbha4319664

608 Ziętkiewicz E, Rafalski A, Labuda D. 1994. Genome fingerprinting by simple sequence repeat 609 (SSR)-anchored polymerase chain reaction amplification. Genomics 20: 176-183. 610 doi:10.1006/geno.1994.1151

611

\section{BIOSKETCH}

613 All the authors work at the Institute for Research on Biodiversity of the Faculty of Biology. Current 614 projects include the study of the ecology, biogeography and conservation genetics of different species of 615 plants and animals in Poland and beyond. 
616

617

618

619

620

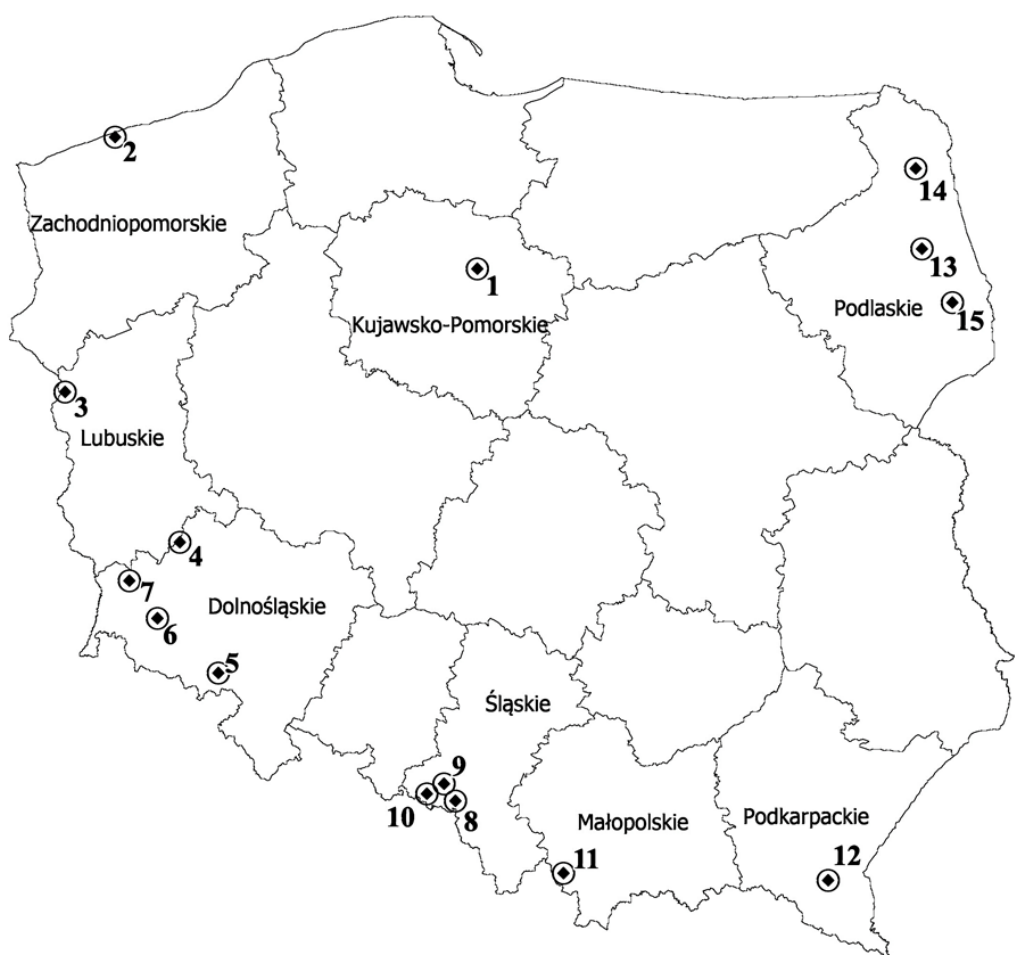

622

623

Figure 1:

624

Map depicting the locations of the 15 populations of $P$. pratensis used in the study.

625 1 - pom06 175; 2 - zap00 240; 3 - lbs05 170; 4 - lbs05 628; 5 - dos01 333; 6 - dos01 405; 7 626 $\operatorname{dos} 01468 ; 8$ - bes03 373; 9 - bes03 379; 10 - bes03 35; 11 - ora03 178; 12 - bie04 189; 13 -

627 $\operatorname{pod} 02215 ; 14-\operatorname{pod} 02172 ; 15-\operatorname{pod} 02317$

628

629

630

631

632

633

634

635

636 
637

638

639

640

641

642

643

644

\section{5}

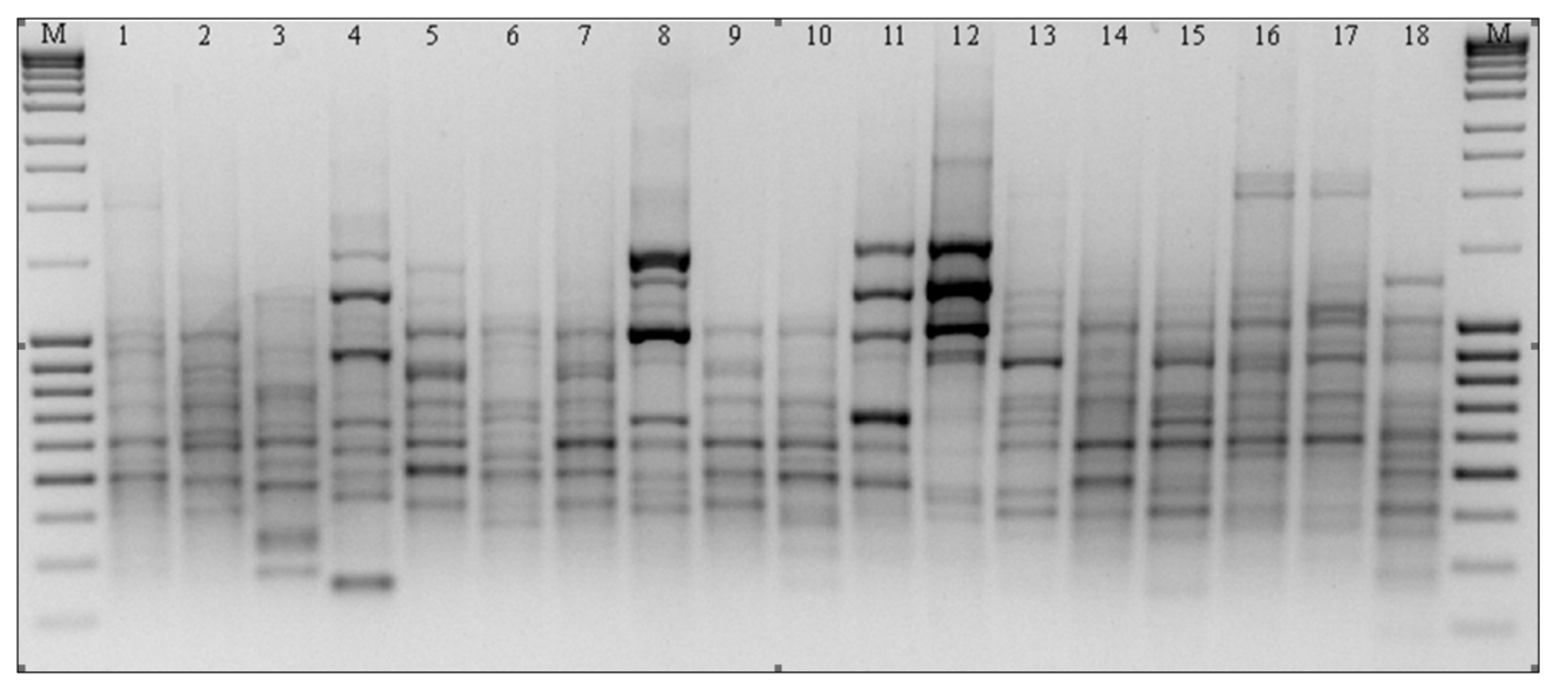

646

647 Figure 2:

648 RAPD patterns amplified with primer M14 for $\boldsymbol{P}$. pratensis.

649 M - MassRuler ${ }^{\mathrm{TM}}$ Ladder Mix, ready-to-use (Thermo Scientific); 1 - pom06 175; 2 - zap00 240;

$6503-\operatorname{lbs} 05170 ; 4-\operatorname{lbs} 05$ 628; $5-\operatorname{dos} 01333 ; 6-\operatorname{dos} 01405 ; 7-\operatorname{dos} 01468 ; 8-\operatorname{bes} 03$ 373; $9-$

651 bes03 379; 10 - bes03 354; 11 - ora03 178; 12 - bie04 189; 13 - pod02 215; 14 - pod02 172; 15

652 - pod02 317; 16 - 'Alicia'; 17 - 'Limousine'; 18 - 'Eska 46'

653

654 
655

656

657

658

659

660

661

662

663

664

665

666

667

668

669

670

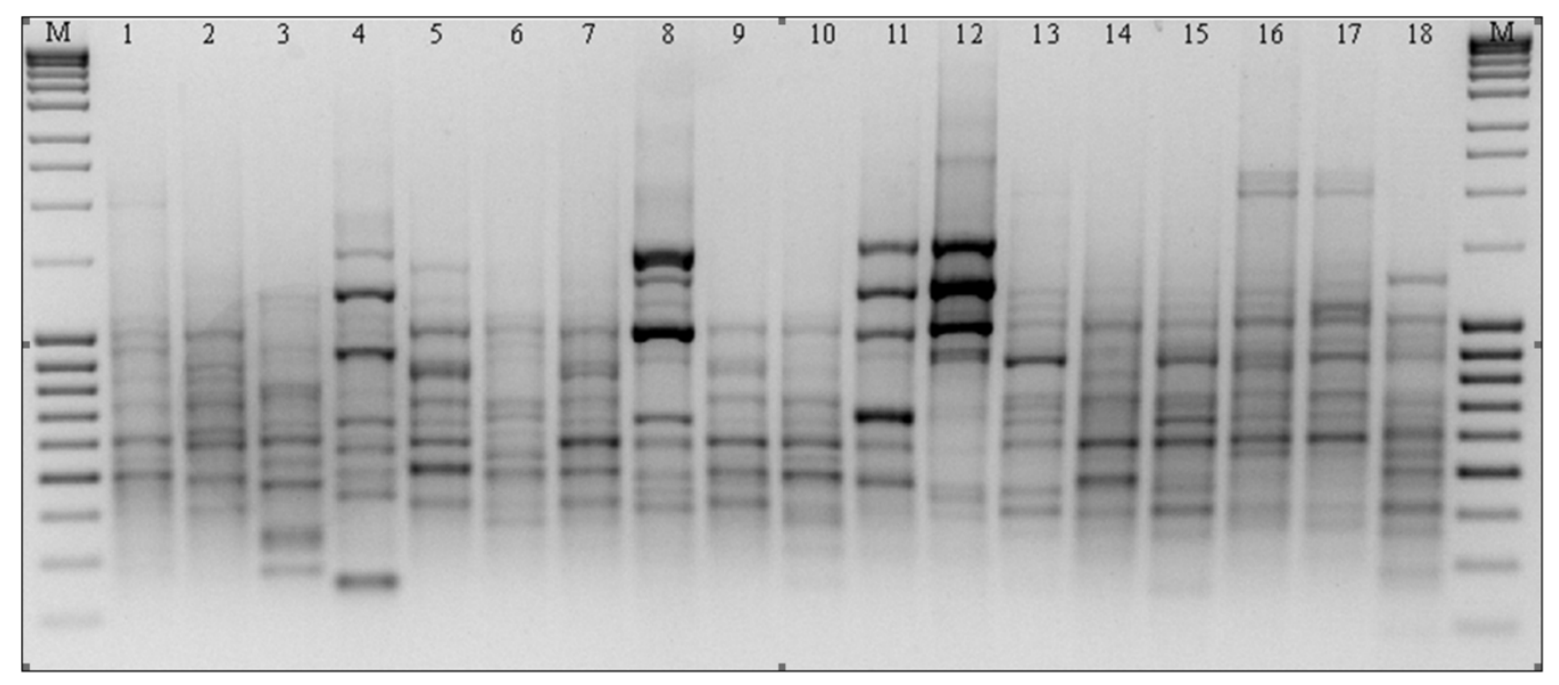

\section{Figure 3:}

ISSR patterns amplified with primer 808 for $P$. pratensis.

M - MassRuler ${ }^{\mathrm{TM}}$ Ladder Mix, ready-to-use (Thermo Scientific); 1 - pom06 175; 2 - zap00 240; 3 - lbs05 170; 4 - lbs05 628; 5 - dos01 333; 6-dos01 405; 7 - dos01 468; 8 - bes03 373; 9 bes03 379; 10 - bes03 354; 11 - ora03 178; 12 - bie04 189; 13 - pod02 215; 14 - pod02 172; 15 - pod02 317; 16 - 'Alicia'; 17 - 'Limousine'; 18 - 'Eska 46' 


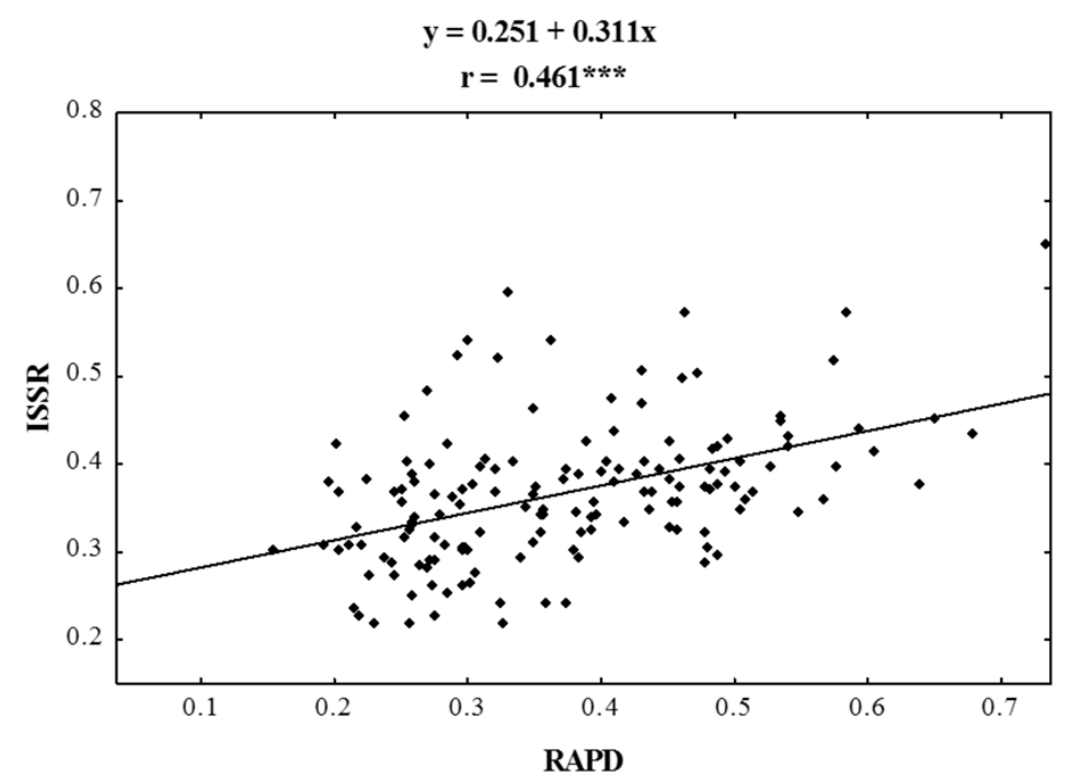

671

672 Figure 4:

673 Correlation analysis of similarity matrices obtained using RAPD and ISSR markers in 674 ecotypes of $P$. pratensis.

675 The symbol *** indicates that the value is significant assuming $\mathrm{P}=0.001$ as the level of 676 significance.

677

678

679

680

681

682

683

684

685

686

687

688

689

690

691

692

693

694

695 

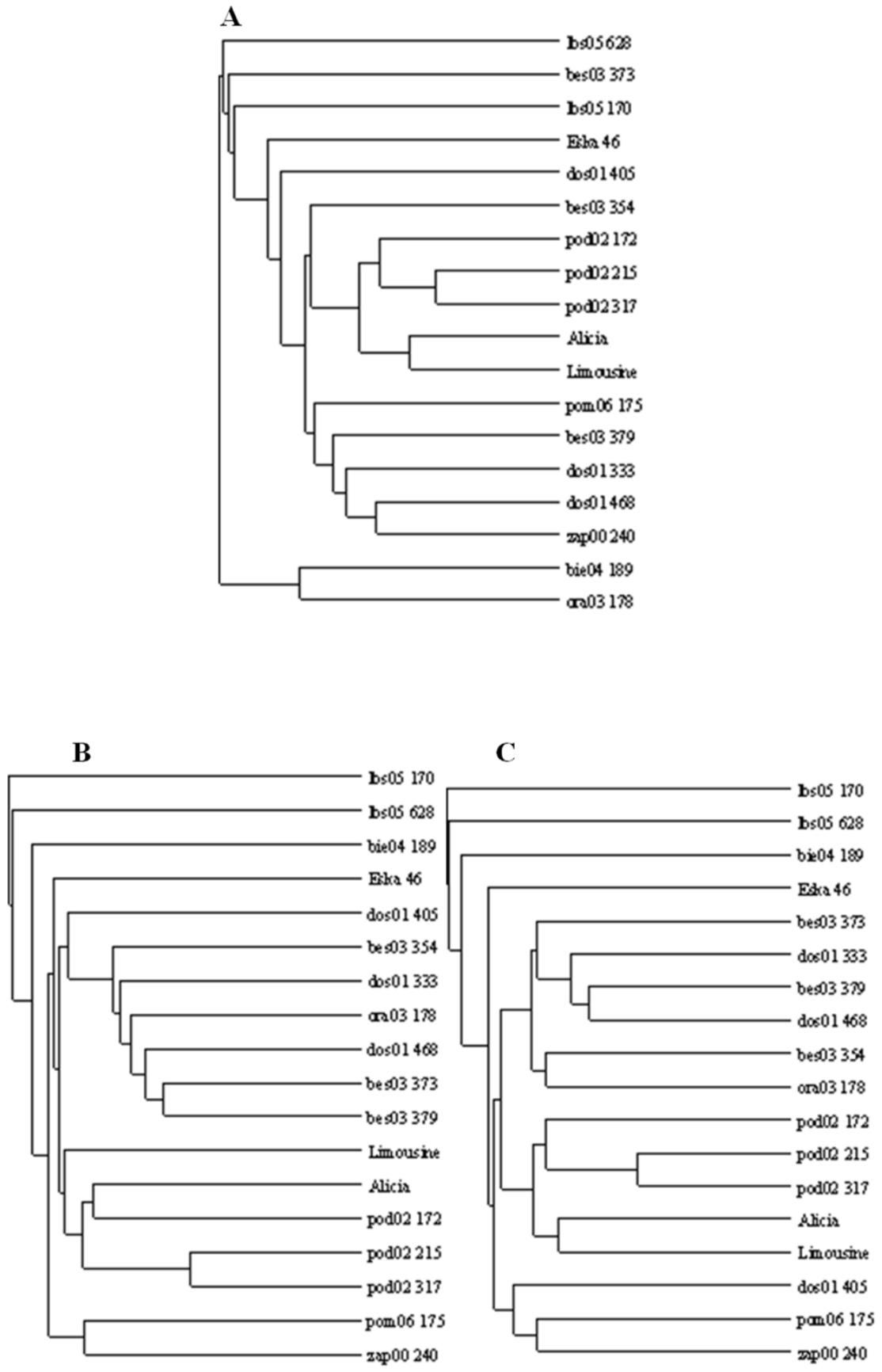

698 Figure 5:

699 UPGMA dendrograms of genetic similarity of the studied ecotypes and cultivars of $P$. 700 pratensis obtained on the basis of polymorphism markers constructed using the TreeView $701 \quad$ 1.6.6.

702 A - RAPD, B - ISSR, C - (RAPD+ISRR) 
A

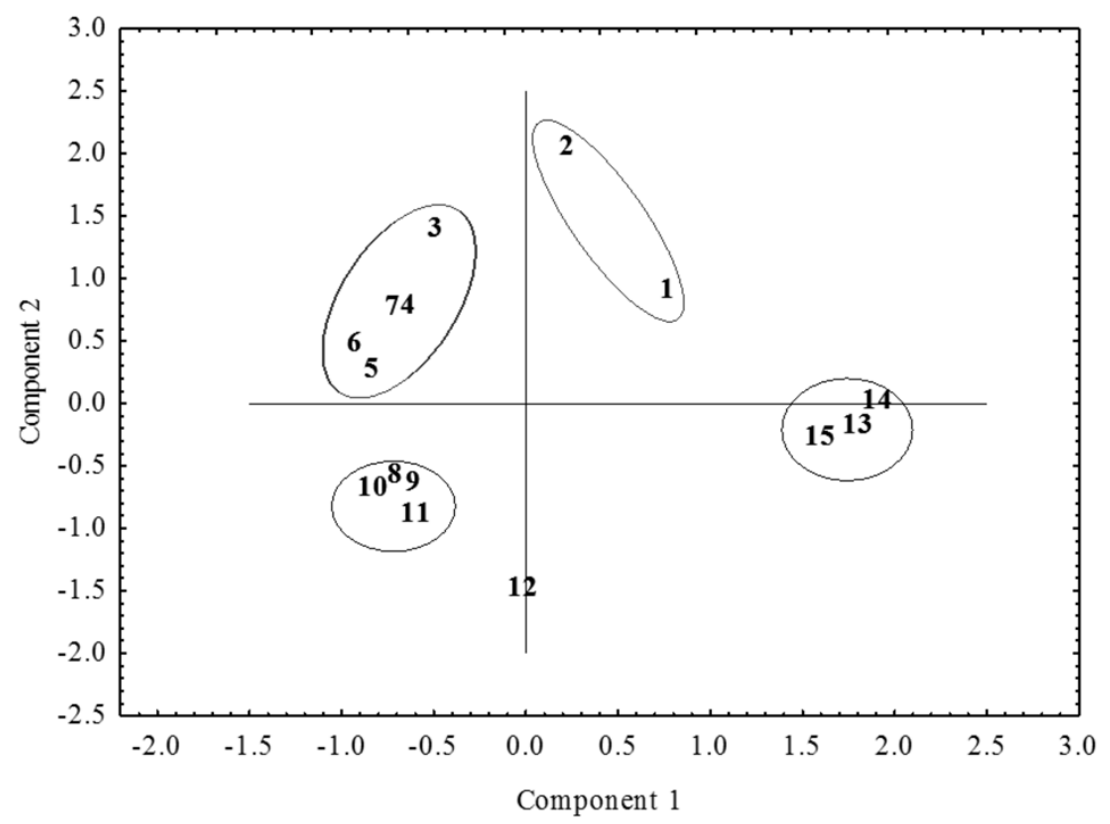

B

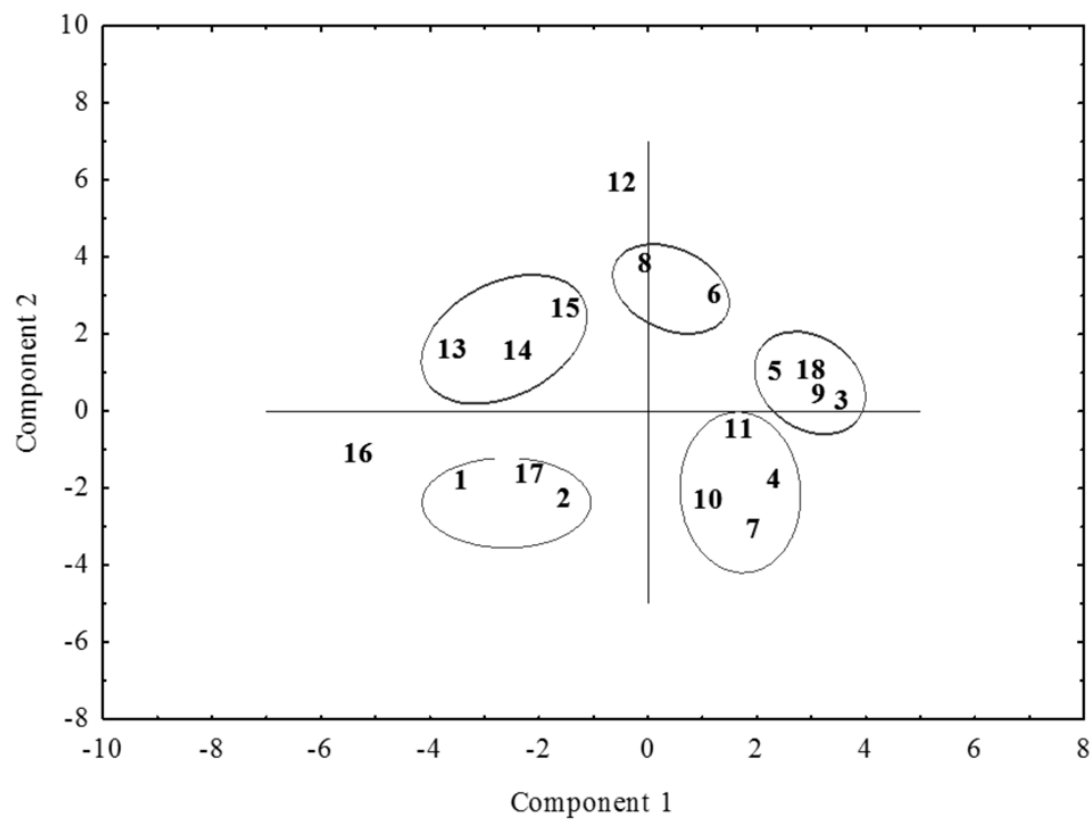
dimensional space (PCA). A - the result for the initial data in the form of geographic coordinates of their habitats.

$708 \mathrm{~B}-$ the final result of PCA analysis using the size of the amplification products generated in the presence 709 of four ISSR primers: $807,808,834,840$, the closest to the geographical location of the selected 710 ecotypes: 1 - pom06 175; 2 - zap00 240; 3 - lbs05 170; 4 - lbs05 628; 5 - dos01 333; 6 - dos01 405; 7 - 
711 dos01 468; 8 - bes03 373; 9 - bes03 379; 10 - bes03 354; 11 - ora03 178; 12 - bie04 189; 13 -

712 pod02 215; 14 - pod02 172; 15 - pod02 317; 16 - 'Alicia'; 17 - 'Limousine'; 18 - 'Eska 46'

713

714 Table 1:

715 Ecotypes of $\boldsymbol{P}$. pratensis analyzed in the study and the locations where their caryopses were 716 collected.

717

718

\begin{tabular}{|c|c|c|c|c|}
\hline Ecotype & Town/Place & Latitude & Longitude & Habitat \\
\hline pom06 175 & Wielkie Stwolno & $53^{\circ} 26^{\prime} 34.1^{\prime \prime N} \mathrm{~N}$ & $18^{\circ} 39^{\prime} 25.8^{\prime \prime} \mathrm{E}$ & Vistula River oxbow lake \\
\hline zap00 240 & Łukęcin & $54^{\circ} 02^{\prime} 58.4^{\prime \prime} \mathrm{N}$ & $14^{\circ} 52^{\prime} 03.7^{\prime \prime E}$ & beach \\
\hline lbs05 170 & Owczary & $52^{\circ} 28^{\prime} 16.3^{\prime \prime} \mathrm{N}$ & 14039'08.0"E & Ostnicowy nature reserve \\
\hline lbs05 628 & Przemków & $51^{\circ} 32^{\prime} 50.6^{\prime \prime N}$ & $15^{\circ} 46^{\prime} 33.4^{\prime} \mathrm{E}$ & meadow \\
\hline $\operatorname{dos} 01333$ & Rybnica Leśna II & $50^{\circ} 42^{\prime} 08.5^{\prime \prime} \mathrm{N}$ & $16^{\circ} 18^{\prime} 00.3^{\prime \prime} \mathrm{E}$ & pasture \\
\hline $\operatorname{dos} 01405$ & Dziwiszów - Góry Kaczawskie & $50^{\circ} 57^{\prime} 39.4^{\prime \prime N}$ & $15^{\circ} 49^{\prime} 23.6^{\prime \prime E}$ & meadow \\
\hline $\operatorname{dos} 01468$ & Oleszna Podgórska & $51^{\circ} 21^{\prime} 02.3^{\prime \prime} \mathrm{N}$ & $15^{\circ} 28^{\prime} 12.1 " \mathrm{E}$ & meadow \\
\hline bes03 373 & Ustroń - Wielka Czantoria & $49^{\circ} 40^{\prime} 45.6^{\prime \prime} \mathrm{N}$ & $18^{\circ} 47^{\prime} 42.7^{\prime \prime E}$ & mountain meadow \\
\hline bes03 379 & Ustroń - Polana Goryczkowa & $49^{\circ} 41^{\prime} 05.6^{\prime \prime} \mathrm{N}$ & $18^{\circ} 46^{\prime} 58.6^{\prime \prime} \mathrm{E}$ & meadow pasture \\
\hline bes03 354 & Jaworzynka & $49^{\circ} 31^{\prime} 20.2^{\prime \prime} \mathrm{N}$ & 18051'31.2"E & meadow \\
\hline ora03 178 & Lipnica Wielka & $49^{\circ} 27^{\prime} 05.3^{\prime \prime} \mathrm{N}$ & $19^{\circ} 37^{\prime} 40.6^{\prime \prime E}$ & meadow \\
\hline bie04 189 & Płonna & $49^{\circ} 26^{\prime} 11.7^{\prime \prime} \mathrm{N}$ & $22^{\circ} 07^{\prime} 05.9^{\prime \prime} \mathrm{E}$ & wasteland \\
\hline pod02 215 & Lipina & $53^{\circ} 19^{\prime} 59.6^{\prime \prime N}$ & $23^{\circ} 25^{\prime} 28.5^{\prime \prime} \mathrm{E}$ & meadow/pasture \\
\hline pod02 172 & Walne & $53^{\circ} 58^{\prime} 20.0^{\prime \prime} \mathrm{N}$ & $23^{\circ} 04^{\prime} 04.6^{\prime \prime} \mathrm{E}$ & meadow \\
\hline pod02 317 & Pieńki & $53^{\circ} 03^{\prime} 32.3^{\prime \prime} \mathrm{N}$ & $23^{\circ} 38^{\prime} 47.2^{\prime \prime E}$ & pasture \\
\hline
\end{tabular}

719

720

721

722

723

724

725

726

727

728

729

730 
Table 2:

The sequences of primers used in the study.

Random amplification of polymorphic DNA was held in the presence of 7 10-nucleotide primers manufactured by Oligo IBB PAN, Poland. 13 microsatellite primers were used for the ISSR-PCR

742

743

744

745

746

747

748

749

750

751

752

753

754

755

756

757

758 reaction. Most of them were dinucleotides composed of 17 and $18 \mathrm{bp}$.

759

760

Notes:

\begin{tabular}{cccc}
\hline $\begin{array}{c}\text { Primer } \\
\text { RAPD }\end{array}$ & $\begin{array}{c}\text { Sequence } \\
5^{\prime}-3^{\prime}\end{array}$ & $\begin{array}{c}\text { Primer } \\
\text { ISSR }\end{array}$ & $\begin{array}{c}\text { Sequence } \\
5^{\prime}-3^{\prime}\end{array}$ \\
\hline B10 & CTGCTGGGAC & 807 & $(\mathrm{AG})_{8} \mathrm{~T}$ \\
B17 & AGGGAACGAG & 808 & $(\mathrm{AG})_{8} \mathrm{C}$ \\
C16 & CACACTCCAG & 810 & $(\mathrm{GA})_{8} \mathrm{~T}$ \\
F05 & CCGAATTCCC & 811 & $(\mathrm{GA})_{8} \mathrm{C}$ \\
G19 & GTCAGGGCAA & 834 & $(\mathrm{AG})_{8} \mathrm{YT}$ \\
M14 & AGGGTCGTTC & 840 & $(\mathrm{GA})_{8} \mathrm{YT}$ \\
P08 & ACATCGCCCA & 841 & $(\mathrm{GA})_{8} \mathrm{YC}$ \\
& & 857 & $(\mathrm{AC})_{8} \mathrm{YG}$ \\
& & 888 & $\mathrm{BDB}(\mathrm{CA})_{7}$ \\
& & $\mathrm{R} 07$ & $(\mathrm{AC})_{8} \mathrm{YT}$ \\
& & $\mathrm{M} 09$ & $(\mathrm{AC})_{8} \mathrm{YG}$ \\
& & $\mathrm{N} 01$ & $\mathrm{CA}(\mathrm{GT})_{8}$ \\
& & $\mathrm{TGA}$ & $(\mathrm{TGA})_{6} \mathrm{~A}$ \\
\hline
\end{tabular}

761

Y: T or C; B: C, G or T; D: A, G or T

762

763

764

765

766

767

768

769 
Table 3:

780 RAPD and ISSR primers used, total number of scored bands (NSB), number of 781 polymorphic bands (NPB), their unique bands (NUB) and percentage of polymorphism 782 bands (PPB) for each primer.

\begin{tabular}{cccccc}
\hline $\begin{array}{c}\text { Name } \\
\text { of } \\
\text { primer }\end{array}$ & $\begin{array}{c}\text { Size } \\
\text { range } \\
\text { (bp) }\end{array}$ & NSB & NPB & NUB & PPB \\
\hline \multicolumn{5}{c}{ RAPD } \\
\hline B10 & $213-1867$ & 35 & 35 & 11 & 100 \\
B17 & $209-1483$ & 32 & 32 & 7 & 100 \\
C16 & $149-2367$ & 33 & 33 & 15 & 100 \\
F05 & $316-2366$ & 34 & 34 & 11 & 100 \\
G19 & $201-1902$ & 43 & 43 & 9 & 100 \\
M14 & $226-2243$ & 43 & 43 & 16 & 100 \\
P08 & $179-1173$ & 26 & 26 & 10 & 100 \\
Total & $149-2367$ & 246 & 246 & 79 & - \\
\hline & & ISSR & & & \\
807 & $341-1974$ & 23 & 23 & 1 & 100 \\
808 & $325-3105$ & 43 & 43 & 17 & 100 \\
810 & $338-2523$ & 35 & 35 & 8 & 100 \\
811 & $303-2748$ & 40 & 40 & 10 & 100 \\
834 & $404-2686$ & 35 & 34 & 7 & 97 \\
840 & $373-2967$ & 50 & 50 & 8 & 100 \\
841 & $373-2504$ & 37 & 36 & 7 & 97 \\
857 & $380-2577$ & 46 & 45 & 7 & 98 \\
888 & $501-2414$ & 26 & 24 & 5 & 92 \\
R07 & $576-2327$ & 37 & 37 & 13 & 100 \\
M09 & $353-2096$ & 47 & 47 & 9 & 100
\end{tabular}




\begin{tabular}{cccccc} 
N01 & $404-2256$ & 51 & 51 & 15 & 100 \\
TGA & $362-2209$ & 44 & 43 & 17 & 98 \\
Total & $303-3105$ & 514 & 508 & 124 & - \\
\hline
\end{tabular}

783

784

785

786

787

788

789

790

791

792

793

794

795

796

797

798

Table 4:

799 The average Number of Scored Bands (NSB) including Number of Unique Bands (NUB)

800 obtained in the presence of a single primer, the value of Polymorphism Information Content 801 (PIC), Assay Efficiency Index (AEI), and Genetic Similarity (Si).

802

\begin{tabular}{cccc}
\hline Parameter/Index & RAPD & ISSR & RAPD+ISSR \\
\hline NSB & 35.1 & 38.0 & 36.8 \\
NUB & 11.3 & 7.7 & 9.3 \\
AEI & 35.1 & 37.3 & 36.4 \\
PIC & 0.264 & 0.270 & 0.268 \\
\hline Si & 0.371 & 0.367 & 0.369 \\
(range) & $(0.154-0.733)$ & $(0.218-0.650)$ & $(0.222-0.678)$ \\
\hline
\end{tabular}

803

804

805

806

807

808 